\title{
Zika Virus Infection and the Flint, Michigan, Water Crisis: A Study in Surprising Commonalities
}

\author{
Yasmin Khan, MD, MPH; Daniel J. Barnett, MD, MPH
}

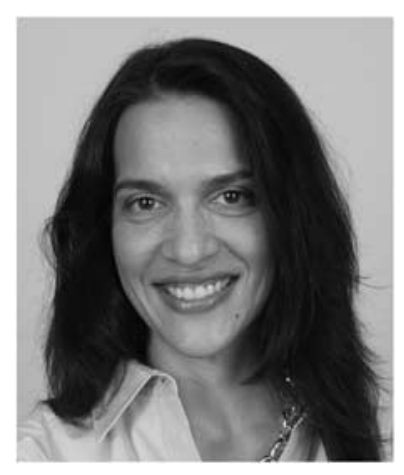

T ead contamination in the drinking water of a US Rust Belt city seems to have little in common with a mosquito-borne viral outbreak creating global infectious disease concern. However, the water crisis in Flint, Michigan, has important similarities to the Zika virus in South America, relevant to the field of disaster medicine and public health preparedness. As we face emerging infectious diseases, complex environmental hazards, and the potential for ongoing health risks due to climate change, these seemingly disparate crises underscore pressing challenges and priorities for this field. ${ }^{1}$

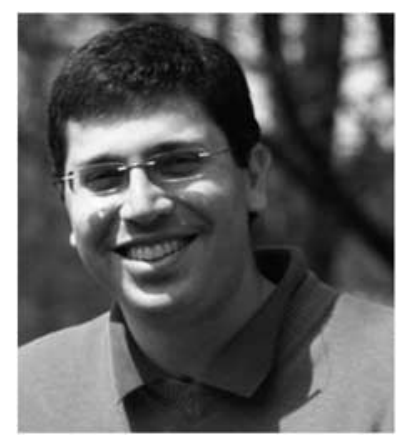

Disaster medicine and public health preparedness is at the intersection of a myriad of disciplines, including clinical medicine, public health, epidemiology, risk sciences, social sciences, and engineering. Each aspect is as pertinent to natural infectious diseases as to anthropogenic environmental crises, necessitating a trans-disciplinary approach to addressing health risks. All-hazards preparedness and response comprise activities such as surveillance, risk assessment, and communication. These activities engage a range of interlinked stakeholders and often cross jurisdictional boundaries. The complexity of this system with multiple organizations, sectors, and disciplines is significant, and yet the capacity of elements in the system to interact and adapt to the changing environment is crucial to health protection for all-hazards emergencies.

A vital and challenging activity in all-hazards preparedness, response, and recovery is communication to the general public and other stakeholders. In the situations of Zika and Flint, Michigan, both crises present grave risk to specific populations: namely, associations with infant microcephaly (Zika) and potential lead-related neurocognitive deficits in children (Flint). The general public and those responding to an event deserve rigorous, evidence-informed approaches to identifying and communicating risk throughout the emergency management cycle. Moreover, the high-risk populations in a particular event require a flexible and adaptable communication approach, which acknowledges health equity, recognizes unique contexts, and leverages community assets. ${ }^{2}$

The abovementioned commonalities across these 2 events highlight the all-hazards practical relevance of disaster medicine and public health preparedness. The field must continuously adapt to a range of threats to population health. However, the field must also mobilize to ensure that rigorous research is done so that, collectively, we can evaluate our preparedness, response, and recovery efforts, and enhance them. The paucity of evidence to inform practice in this domain has been noted. ${ }^{3,4}$ There are, however, examples of research conducted related to recent events that provided valuable knowledge to inform practice., ${ }^{5,6}$ Like all emerging events, Zika and Flint represent lenses for us to understand how we are doing and how we can improve. Frameworks to conceptualize the system for relevant contexts globally can enable more metrically driven quality improvement. The field stands to benefit from rigorous approaches to continuous quality improvement.

Zika and Flint represent currently evolving events; however, it is expected that a broad diversity of all-hazards threats will continue to arise. The complexity of the field is important to 
acknowledge in research, as is the value of studying complex actions like communication and the health equity considerations that are often inherent in disaster risk. As a dynamic trans-disciplinary field, rigorous research, evaluation, and quality improvement will promote critical system capacity for addressing future emergent threats to population health.

Department of Communicable Diseases

Emergency Preparedness and Response

Public Health Ontario

Division of Emergency Medicine, Department of Medicine

University of Toronto

Toronto, Ontario, Canada

Department of Environmental Health Sciences

Johns Hopkins Bloomberg School of Public Health

Baltimore, Maryland

dbarnett@jhsph.edu

\section{REFERENCES}

1. Watts N, Adger WN, Agnolucci P, et al. Health and climate change: policy responses to protect public health. Lancet. 2015;386(10006):1861-1914. http://dx.doi.org/10.1016/S0140-6736(15)60854-6.

2. O'Sullivan TL, Kuziemsky CE, Toal-Sullivan D, et al. Unraveling the complexities of disaster management: A framework for critical social infrastructure to promote population health and resilience. Soc Sci Med. 2013;93:238-246. http://dx.doi.org/10.1016/j.socscimed.2012.07.040.

3. Khan Y, Fazli GS, Henry B, et al. The evidence base of primary research in public health emergency preparedness: a scoping review and stakeholder consultation. BMC Public Health. 2015;15(1):432. http://dx.doi.org/ 10.1186/s12889-015-1750-1.

4. Challen K, Lee ACK, Booth A, et al. Where is the evidence for emergency planning: a scoping review. BMC Public Health. 2012;12(1):542. http://dx. doi.org/10.1186/1471-2458-12-542.

5. Lurie N, Manolio T, Patterson AP, et al. Research as a part of public health emergency response. N Engl J Med. 2013;368(13):1251-1255. http://dx.doi. org/10.1056/NEJMsb1209510.

6. Généreux M, Petit G, Maltais D, et al. The public health response during and after the Lac-Mégantic train derailment tragedy: a case study. Disaster Health. 2014;2(3-4):113-120. http://dx.doi.org/10.1080/21665044. 2014.1103123.
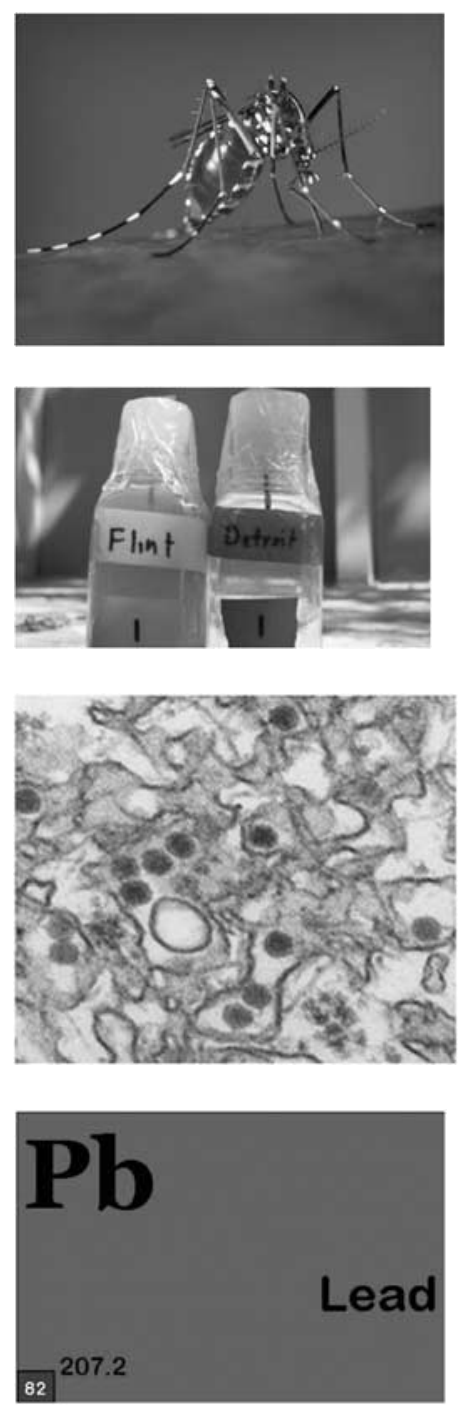

Zika virus is transmitted by the Aedes aegypti mosquito. Image courtesy of CDC.

Flint Water Crisis. Courtesy of Michigan ACLU, http://www.aclumich.org/flint-water-crisis.

Digitally colorized transmission electron micrograph (TEM) of Zika virus. CDC/ Cynthia Goldsmith

Symbol for lead. Periodic Table of Elements. 